\title{
Uso de álcool em vítimas de acidentes de trânsito: estudo do nível de alcoolemia
}

\author{
Ângela Maria Mendes Abreu ${ }^{1}$ \\ Jose Mauro Braz de Lima² \\ Ligia Neres Matos ${ }^{3}$ \\ Sandra Cristina Pillon ${ }^{4}$
}

\begin{abstract}
Trata-se de estudo exploratório descritivo. O objetivo foi correlacionar os níveis de alcoolemia, detectados nas vítimas fatais por acidentes de trânsito, na cidade do Rio de Janeiro, a partir dos registros do Instituto Medico Legal -IML, com o perfil da vítima e as características dos acidentes. Os dados foram levantados no arquivo do IML, por meio dos prontuários de vítimas fatais por acidentes de trânsito, compilados e tabulados Poe meio do programa estatístico SPSS, no período compreendido entre janeiro e maio de 2005. Avaliaram-se 348 prontuários de vítimas fatais por acidentes de trânsito. Desses, apenas 94 realizaram o exame de alcoolemia, sendo que 83 apresentaram alcoolemia positiva e 60,2\% níveis acima de 0,6g/l. Evidenciou-se o envolvimento do álcool com vítimas fatais nos acidentes de trânsito em níveis acima e abaixo de $0,6 \mathrm{~g} / \mathrm{l}$ de álcool por litro de sangue.
\end{abstract}

Descritores: Mortalidade; Acidentes de Trânsito; Alcoolismo; Bebidas Alcoólicas.

\footnotetext{
${ }_{1}^{1}$ Professor Adjunto, Escola de Enfermagem Anna Nery, Universidade Federal do Rio de Janeiro, Brasil. E-mail: angelabreu@globo.com. 2 Professor Associado I, Faculdade de Medicina, Universidade Federal do Rio de Janeiro, Brasil. E-mail: jmbl@evolucaovida.com.br.

${ }^{3}$ Aluna do curso de graduação em Enfermagem, Escola de Enfermagem Anna Nery, Universidade Federal do Rio de Janeiro, Brasil. Bolsista PIBEX. E-mail: ligianeresmatos@terra.com.br.

${ }^{4}$ Enfermeira, Doutor, Professor Doutor, Escola de Enfermagem de Ribeirão Preto, Universidade de São Paulo, Centro Colaborador da OMS para o Desenvolvimento da Pesquisa em Enfermagem, Brasil. E-mail: pillon@eerp.usp.br.
}

Correspondencia:

Sandra Cristina Pillon

Universidade de São Paulo. Escola de Enfermagem de Ribeirão Preto

Av. Bandeirantes, 3900

Bairro Monte Alegre

CEP: 14040-902 Ribeirão Preto, SP, Brasil

E-mail: pillon@eerp.usp.br 


\section{Uso de alcohol en accidentes de tránsito: estudio del nivel de alcoholemia}

Se trata de estudio epidemiológico exploratorio y descriptivo. El objetivo fue correlacionar los niveles de alcoholemia detectados en las víctimas fatales por accidentes de tránsito, en la ciudad de Río de Janeiro (datos de los registros del Instituto Médico Legal/IML) con el perfil de la víctima y las características de los accidentes. Los datos fueron recolectados del archivo del IML, a través de los registros que constaban en las fichas de víctimas fatales por accidentes de tránsito; fueron compilados y se elaboraron tablas con el Programa estadístico SPSS, en el período comprendido entre enero y mayo de 2005. Fueron levantados datos sobre 348 víctimas fatales por accidentes de tránsito, de estos, apenas 94 realizaron el examen de alcoholemia, siendo que en 83 fueron detectados niveles de alcoholemia; el 60,2\% presentó niveles por encima de 0,6g de alcohol por litro de sangre. Se mostró evidente el envolvimiento del alcohol en accidentes de tránsito con víctimas fatales, en niveles por encima y por debajo de $0,6 \mathrm{~g}$ de alcohol por litro de sangre.

Descriptores: Mortalidad; Accidentes de Tránsito; Alcoholismo; Bebidas Alcohólicas.

\section{Alcohol use And Traffic Accidents: a Study of Alcohol Levels}

This was an exploratory, descriptive study that aimed to correlate alcohol levels detected in fatal victims of traffic accidents, in Rio de Janeiro city, with the victim's profile and the characteristics of the accident. The data were retrieved from the registers of the Legal Medicine Institute/IML, through the registers of the medical records of the fatal victims of traffic accidents. Compiled and tabulated using the Statistics Program SPSS, for the period between January and May 2005, 348 fatal victims of traffic accidents were reported. Of these victims, 94 had been tested for alcohol, of these, 83 had levels of alcohol detected, $60.2 \%$ presented levels above $0.6 \mathrm{~g} / \mathrm{l}$ blood. The use of alcohol was evident, at levels above and below $0.6 \mathrm{~g}$ per liter of blood, in the cases of fatal victims of traffic accidents.

Descriptors: Mortality; Accidents, Traffic; Alcoholism; Alcoholic Beverages.

\section{Introdução}

Os acidentes de trânsito, como importantes fatos da morbimortalidade geral, são considerados, hoje, verdadeiro problema de saúde pública em muitos países, em especial no Brasil. Estima-se que mais de 1,2 milhão de pessoas morrem por ano no mundo e cerca de 50 milhões sofrem lesões, sendo que de 15 a 20\% dessas lesões apresentam sequelas diversas(1).

Projeções para o ano 2020 apontam que os acidentes de trânsito ocuparão o terceiro lugar nas causas gerais de mortalidade mundial, no entanto, essa projeção só se concretizará se os países de baixa e média renda não adotarem medidas necessárias a respeito, sobretudo os países em desenvolvimento(1).
No Brasil, em 2005, o número de mortos por acidentes de trânsito atingiu índices consideráveis. Estudo demonstrou que, no período de 1990 a 2005, houve aumento de $72 \%$ dos óbitos em municípios com menos de 100 mil habitantes ${ }^{(2)}$. Ainda, no que concerne à morbidade (feridos muitas vezes graves e com sequelas), estima-se que 400.000 pessoas/ano sofreram algum tipo de ferimento decorrente de acidentes de trânsito(3).

De forma geral, em vários países, estudos vêm apontando o consumo de bebidas alcoólicas como um dos principais fatores responsáveis pela alta incidência dos acidentes com vítimas ${ }^{(3-5)}$. No Brasil, esse consumo também é apontado como um dos principais fatores 
causais de acidentes. Em aproximadamente 70\% dos acidentes violentos com mortes, no trânsito, o álcool é o principal responsável(3). No entanto, ainda que estudos venham apontando essa relação, pouco se tem estudado, no Brasil, a ocorrência do acidente e o nível de alcoolemia da vítima, no momento do mesmo ${ }^{(4-5)}$.

Ao comparar a relevância do impacto do álcool nos acidentes de trânsito, no Brasil, existe significante subestimação e subnotificação em relação a outros países com situação semelhante ${ }^{(6)}$.

No Brasil, até junho de 2008, o limite tolerado de alcoolemia, conforme recomendado pelo Código de Trânsito Brasileiro, era de $0,6 \mathrm{~g}$ de álcool por litro de sangue(7).

$\mathrm{Na}$ concentração de $0,6 \mathrm{~g} / \mathrm{l}$ de sangue, de acordo com a associação de outros fatores, e dependendo da sensibilidade individual, o álcool pode provocar no cérebro alterações neurofuncionais suficientes para ocasionar mudanças de comportamento facilitadoras da violência e outras consequências como, por exemplo, dirigir $^{(3)}$.

Embora seja reconhecido que o consumo de bebidas alcoólicas aumenta efetivamente o risco de acidentes de trânsito, esse se torna mais grave e com mais vítimas fatais. Ainda é difícil estabelecer comparações entre os diversos estudos, devido às grandes variações que existem de um país para o outro, nos limites legais de alcoolemia impostos pela legislação local(1). Como exemplo, pode-se citar os valores diferenciados estabelecidos em países da América Latina como: Argentina - 0,5g/l, Chile - 0,5g/l, El Salvador - 1,0g/l, México - 0,8g/l, Peru até $0,6 \mathrm{~g} / \mathrm{l}$ e outros, onde nem sequer existem normas a respeito, como Cuba, Bolívia, Haiti, Paraguai, entre outros ${ }^{(8)}$.

Na França, há alguns anos, após a instituição de legislação pertinente mais severa, o nível de alcoolemia de $0,2 \mathrm{~g} / \mathrm{l}$ foi recomendado para condutores de veículos de transportes de passageiros e de carga, apesar de a taxa de $0,5 \mathrm{~g} / \mathrm{l}$ ser ainda tolerada para os demais condutores $^{(9)}$.

Segundo pesquisa realizada na cidade do Rio de Janeiro, sobre a mortalidade nos acidentes de trânsito relacionados à alcoolemia, observou-se que 181 $(42,5 \%)$ das vitimas que foram submetidas ao exame apresentaram índices de alcoolemia entre 0,1 e 0,6g/l de sangue ${ }^{(10)}$. O que permite refletir a respeito do real limite de tolerância do álcool no organismo, já que havia vítimas fatais de acidentes de trânsito que apresentavam concentrações de álcool, no sangue, inferiores às toleradas pela legislação brasileira, pois, no período, o limite considerado pelos parâmetros da legislação sobre os níveis de alcoolemia era de até $0,6 \mathrm{~g} / \mathrm{l}$ de álcool no sangue(7). $^{(7)}$

Estima-se que o risco para sofrer acidentes, após consumo de bebidas alcoólicas, aumenta consideravelmente. No entanto, mesmo em casos com alcoolemia inferior a $0,6 \mathrm{~g} / \mathrm{l}$ de sangue no organismo, o risco de sofrer acidentes de trânsito graves e com vítimas fatais pode ocorrer com certa frequência, conforme já verificado em relatos anteriores ${ }^{(4)}$.

Dessa forma, o estudo teve como objetivo avaliar os níveis de alcoolemia das vítimas fatais por acidentes de trânsito, na cidade do Rio de Janeiro, por meio de dados secundários - registros do IML -, identificandose, assim, o perfil da vítima e as características dos acidentes.

\section{Método}

O desenho metodológico do estudo foi do tipo descritivo, obtido por meio de dados secundários, realizado no IML, da cidade do Rio de Janeiro, local para onde todas as vítimas fatais, envolvidas em causas violentas, são encaminhadas. Coletaram-se dados dos prontuários de todas as vítimas de trânsito, nos meses de janeiro a maio de 2005, por meio das informações descritas nos formulários do referido IML. Dessa forma, identificaram-se 348 (100\%) vítimas de acidentes de trânsito no período. Considerou-se acidente de trânsito todo acidente ocorrido com veículo em via pública.

As variáveis estudadas estavam relacionadas às características sociodemográficas das vítimas como: faixa etária, sexo, cor/raça, estado civil e as características dos acidentes como: turno (manhã das 6 às $11 \mathrm{~h} 59$, tarde das 12 às $17 \mathrm{~h} 59$, noite das 18 às 23h59 e madrugada de 0 às 5h59), dia da semana, local do óbito, tipo de acidente, realização do exame de alcoolemia e níveis de alcoolemia. A técnica utilizada para detectar a alcoolemia foi a da cromatografia gasosa, a qual possibilita a detecção dos níveis de álcool no sangue $\geq 0,1 \mathrm{~g} / \mathrm{l}$.

A análise estatística foi realizada por meio do programa SPSS (versão 12). Análises univariadas e bivariadas foram realizadas. O teste de qui-quadrado foi utilizado para avaliar a associação entre variáveis categóricas, com intervalo de confiança de 5\%.

Estabeleceu-se como ponto de corte para discussão da alcoolemia os níveis abaixo e acima de $0,6 \mathrm{~g} / \mathrm{l}$ de sangue, de acordo com o limite de tolerância, estabelecido na lei vigente do país à época, conforme o Código Brasileiro de Trânsito de 1997(7). 
Vale ressaltar que esse estudo foi realizado antes da atual Lei 11.705, de 19 de junho de 2008, que estabeleceu alcoolemia zero para os condutores de veículos automotores em todo país(11).

O projeto de pesquisa foi aprovado pelo Comitê de Ética e Pesquisa do Instituto Médico Legal, em novembro de 2005, Protocolo n¹21/1544 D/ GAB/05.

\section{Resultados}

A Tabela 1 demonstra que, no período do estudo, houve $348(100 \%)$ vítimas de acidentes de trânsito, dessas, 254 (73\%) não realizaram o exame, indicando, dessa forma, alta frequência de exames de alcoolemia não realizados nas vítimas fatais quando chegaram ao IML. Por outro lado, observa-se que em 94 (27\%) das vitimas foi realizado o exame de alcoolemia. Dentre aqueles nos quais foram realizados os exames, $11(11,7 \%)$ vítimas apresentaram alcoolemia negativa, isto é, não foi detectada a presença de álcool no sangue (alcoolemia $\leq 0,0)$. Das $83(23,8 \%)$ vítimas que apresentaram níveis de alcoolemia, 33 (39,8\%) apresentaram níveis menores que $0,6 \mathrm{~g} / \mathrm{l}$, indicando percentual significativo de mortalidade com níveis abaixo do limite de tolerância legal, estabelecido pelo Código de Trânsito Brasileiro, até junho de 2008.

Tabela 1 - Níveis de alcoolemia em vítimas com óbito por acidentes de trânsito, Instituto Médico Legal -IML, RJ, $2005(n=348)$

\begin{tabular}{|c|c|c|c|c|c|c|c|}
\hline \multicolumn{4}{|c|}{ Alcoolemia* } & \multicolumn{4}{|c|}{ Alcoolemia ${ }^{* * *}$} \\
\hline \multicolumn{2}{|c|}{ Realizado } & \multicolumn{2}{|c|}{ Não realizado } & \multicolumn{2}{|c|}{$\begin{array}{c}\text { Acima de } \\
0,6 \mathrm{~g} / \mathrm{l}\end{array}$} & \multicolumn{2}{|c|}{$\begin{array}{c}\text { Abaixo de } \\
0,6 \mathrm{~g} / \mathrm{l}\end{array}$} \\
\hline $\mathbf{n}$ & $\%$ & $\mathbf{n}$ & $\%$ & $\mathbf{n}$ & $\%$ & $\mathbf{n}$ & $\%$ \\
\hline 94 & 27 & 254 & 73 & 50 & 60,2 & 33 & 39,8 \\
\hline
\end{tabular}

*utilizada a técnica de cromatografia gasosa $(\geq 0,1 \mathrm{~g} / \mathrm{l})$.

** retirado os não detectados (alcoolemia $\leq 0,0)$ )

***mínimo- 0,1g/l; maximo- 3,82g/l; média- 0,95g/l

Observa-se, também, que $50(60,2 \%)$ das vitimas apresentaram níveis de alcoolemia maiores que $0,6 \mathrm{~g} / \mathrm{l}$, mostrando, dessa forma, o impacto mais evidente nos níveis do álcool no trânsito. Vale ressaltar os resultados dos níveis de alcoolemia que variaram de $0,95 \mathrm{~g} / \mathrm{l}$ de sangue a $3,82 \mathrm{~g} / \mathrm{l}$, indicando que a maioria das vítimas de acidente de trânsito apresentava níveis de alcoolemia bem acima do que estava estabelecido pela lei vigente, no período do estudo, que era de $0,6 \mathrm{~g} / \mathrm{l}$.
Tabela 2 - Informações sociodemográficas das vítimas com óbito por acidentes de trânsito e os níveis de alcoolemia, Instituto Medico Legal -IML, RJ, $2005(n=83)$

\begin{tabular}{|c|c|c|c|c|c|c|c|}
\hline \multirow{3}{*}{ Variáveis } & \multirow{2}{*}{\multicolumn{2}{|c|}{ Total }} & \multicolumn{4}{|c|}{ Alcoolemia } & \multirow{3}{*}{ n } \\
\hline & & & \multicolumn{2}{|c|}{$<0,6 \mathrm{~g} / \mathrm{l}$} & \multicolumn{2}{|c|}{$>0,6 \mathrm{~g} / \mathrm{l}$} & \\
\hline & $n$ & $\%$ & $n$ & $\%$ & $\mathrm{n}$ & $\%$ & \\
\hline Faixa etária & & & & & & & 0,009 \\
\hline 10 a 19 anos & 8 & 9,6 & 4 & 50 & 4 & 50 & \\
\hline 20 a 29 anos & 21 & 25,3 & 7 & 33,3 & 14 & 66,7 & \\
\hline 30 a 39 anos & 11 & 13,2 & 3 & 27,3 & 8 & 72,7 & \\
\hline 40 a 49 e mais & 13 & 15,7 & 2 & 15,4 & 11 & 84,6 & \\
\hline 50 a 59 anos & 9 & 10,9 & 3 & 33,3 & 6 & 66,7 & \\
\hline 60 e mais & 18 & 21,7 & 14 & 77,8 & 4 & 22,2 & \\
\hline Ignorado & 3 & 3,61 & 0 & 0 & 3 & 100 & \\
\hline Sexo & & & & & & & 0,679 \\
\hline Masculino & 72 & 86,7 & 28 & 38,9 & 44 & 61,1 & \\
\hline Feminino & 11 & 13,3 & 5 & 45,5 & 6 & 54,5 & \\
\hline Cor/raça & & & & & & & 0,076 \\
\hline Branco & 41 & 49,4 & 21 & 51,2 & 20 & 48,8 & \\
\hline Mestiço/mulato & 35 & 42,1 & 9 & 25,7 & 26 & 74,3 & \\
\hline Negro & 7 & 8,5 & 3 & 42,9 & 4 & 57,1 & \\
\hline Estado civil & & & & & & & 0,008 \\
\hline Solteiro & 48 & 57,9 & 14 & 29,2 & 34 & 70,8 & \\
\hline Casado & 20 & 24 & 12 & 60 & 8 & 40 & \\
\hline Viúvo & 6 & 7,2 & 5 & 83,3 & 1 & 16,7 & \\
\hline Divorciado & 4 & 4,9 & 2 & 50 & 2 & 50 & \\
\hline Ignorado & 5 & 6 & 0 & 0 & 5 & 100 & \\
\hline
\end{tabular}

A Tabela 2 demonstra que as vítimas fatais de acidentes de trânsito eram, na maioria, jovens adultos, na faixa etária produtiva, sobretudo se se somar o percentual das idades entre 20 e 49 anos. Nota-se, também, que as vítimas de 60 anos ou mais mostravam percentual de $21,7 \%$ em relação à presença de álcool no sangue, no momento do acidente. Por outro lado, ao se avaliar os níveis de alcoolemia, observou-se maior frequência, nessa faixa etária, para níveis abaixo de $0,6 \mathrm{~g} / \mathrm{l}$ de sangue $(77,8 \%)$.

Quando observada a faixa etária dos mais jovens, isto é, na idade de 20 a 49 anos, encontrou-se percentual significativo dos níveis de alcoolemia acima de 0,6g/l, apontando, dessa forma, abuso maior no consumo do álcool, entre os jovens.

Quanto ao sexo, a maioria era pertencente ao sexo masculino $(86,7 \%)$, mostrando ser esse fenômeno visivelmente mais intenso nessa categoria, fato que pode ser atribuído à maior exposição, mediante o comportamento social e cultural dos homens, predispondo-os, em maiores proporções, aos riscos de lesões e mortes. Porém, em relação ao exame de alcoolemia, observa-se que o gênero feminino apresentou frequências iguais tanto para resultados abaixo quanto acima de $0,6 \mathrm{~g} / \mathrm{l}$ de sangue, quando 
comparado ao gênero masculino. Embora não havendo diferença estatística significativa, os dados sugerem que as mulheres também estão envolvidas com o uso do álcool e acidentes de trânsito.

Em relação à cor, a maior frequência de alcoolemia foi identificada entre as vítimas de cor branca $(49,4 \%)$, seguido da cor mulato $(42,1 \%)$. No entanto, ao se avaliar os níveis de alcoolemia, observou-se maior frequência acima de $0,6 \mathrm{~g} / \mathrm{l}$ entre indivíduos mulatos $(74,3 \%)$, seguido da cor negra $(57,1 \%)$ e a cor branca apresentou maior frequência para alcoolemia, abaixo de 0,6g/l (51,2\%), embora não haja estudos disponíveis que explorem essa questão.

Observou-se maior frequência de realização dos exames entre os solteiros, talvez por serem os mais jovens, quando observados os níveis de alcoolemia, também houve maior frequência de alcoolemia acima de $0,6 \mathrm{~g} / \mathrm{l}$, concentrado nessa categoria $(70,8 \%)$. Por outro lado, em relação aos resultados abaixo de $0,6 \mathrm{~g} / \mathrm{l}$, houve maior concentração nos indivíduos da categoria viúvos. O que pode estar relacionado aos resultados da faixa etária, com pessoas de 60 anos e mais, envolvidos com álcool e acidentes de trânsito.

Tabela 3 - Características dos acidentes de trânsito e os níveis de alcoolemia detectados em vítimas com óbito no Instituto Médico Legal -IML, RJ, 2005

\begin{tabular}{|c|c|c|c|c|c|c|}
\hline \multirow{3}{*}{ Variáveis } & \multirow{2}{*}{\multicolumn{2}{|c|}{ Total }} & \multicolumn{4}{|c|}{ Alcoolemia } \\
\hline & & & \multicolumn{2}{|c|}{$<0,6 \mathrm{~g} / \mathrm{l}$} & \multicolumn{2}{|c|}{$>0,6 \mathrm{~g} / \mathrm{l}$} \\
\hline & $\mathrm{n}$ & $\%$ & $\mathrm{n}$ & $\%$ & $\mathrm{n}$ & $\%$ \\
\hline \multicolumn{7}{|l|}{ Período* } \\
\hline Noite & 25 & 33,7 & 14 & 45,1 & 11 & 50 \\
\hline Madrugada & 25 & 33,7 & 6 & 19,3 & 19 & 66,7 \\
\hline Manhã & 12 & 16,2 & 4 & 12,9 & 8 & 72,7 \\
\hline Tarde & 12 & 16,2 & 7 & 22,5 & 5 & 84,6 \\
\hline Total & 74 & 100 & 31 & 100 & 43 & 100 \\
\hline \multicolumn{7}{|l|}{ Dias da semana* } \\
\hline Segunda-feira & 11 & 13,5 & 5 & 15,5 & 6 & 12,5 \\
\hline Terça-feira & 1 & 1,2 & 0 & 0 & 1 & 2 \\
\hline Quarta-feira & 3 & 3,7 & 2 & 6 & 1 & 2 \\
\hline Quinta-feira & 8 & 9,8 & 3 & 9,1 & 5 & 10,4 \\
\hline Sexta-feira & 10 & 12,3 & 3 & 9,1 & 7 & 14,5 \\
\hline Sábado & 24 & 29,6 & 9 & 27,2 & 15 & 31,2 \\
\hline Domingo & 24 & 29,6 & 11 & 33,3 & 13 & 27,1 \\
\hline Total & 81 & 100 & 33 & 100 & 48 & 100 \\
\hline \multicolumn{7}{|l|}{ Local do óbito } \\
\hline Via pública & 54 & 65 & 20 & 60,7 & 34 & 68 \\
\hline Hospital & 29 & 35 & 13 & 39,3 & 16 & 32 \\
\hline Total & 83 & 100 & 33 & 100 & 50 & 100 \\
\hline \multicolumn{7}{|l|}{ Causa do acidente } \\
\hline Queda de moto & 5 & 6 & 4 & 12,1 & 1 & 2 \\
\hline Colisão & 29 & 35 & 10 & 30,3 & 19 & 38 \\
\hline Atropelamento & 49 & 59 & 19 & 57,6 & 30 & 60 \\
\hline Total & 83 & 100 & 33 & 100 & 50 & 100 \\
\hline
\end{tabular}

Observa-se, na Tabela 3, que a maior frequência de exames se mostra nos acidentes que aconteceram no período noturno (noite e madrugada), resultados que, quando somados, perfazem $67,4 \%$, principalmente aqueles que ocorreram de sexta até segunda-feira.

No entanto, ao avaliar o período em que ocorreu o acidente com os níveis de alcoolemia, observou-se que houve maior concentração nos níveis de alcoolemia, acima de $0,6 \mathrm{~g} / \mathrm{l}$, nos acidentes ocorridos no período da tarde $(84,6 \%)$ e da manhã $(72,7 \%)$, com alcoolemia acima de $0,6 \mathrm{~g} / \mathrm{l}$ o perído foi à noite $(45,1 \%)$. Por outro lado, ao se observar os dias da semana, o consumo de álcool ocorre e se apresenta muito associado ao lazer, principalmente no sábado e no domingo, nos horários de descanso. Observa-se que os níveis de alcoolemia acima de $0,6 \mathrm{~g} / \mathrm{l}$ ocorreram mais aos sábados e, abaixo de $0,6 \mathrm{~g} / \mathrm{l}$, mais aos domingos. Esse fato evidencia maior relação de uso do álcool nos fins de semana, acontecendo fora do horário da noite e da madrugada, principalmente no período da tarde.

Quanto ao local em que ocorreu o óbito, observouse que $65 \%$ daqueles nos quais foi foi realizada a alcoolemia eram vítimas provenientes de vias públicas. Embora não apresentando diferenças estatísticas significativas, os valores apontam que quanto maior a gravidade do acidente em via pública maior é o seu envolvimento com o álcool.

Em relação à causa do acidente, o estudo mostrou que a alcoolemia esteve presente em mais da metade das vítimas por atropelamento (59,9\%), com níveis acima de $0,6 \mathrm{~g} / \mathrm{l}$, fato que também ocorreu entre pessoas que apresentaram alcoolemia abaixo de $0,6 \mathrm{~g} / \mathrm{l}$. No entanto em vítimas de colisão esteve presente em $38 \%$ daqueles que apresentaram alcoolemia em níveis acima de 0,6g/l. Esses dados sugerem relação entre a gravidade dos acidentes e os níveis de alcoolemia.

\section{Discussão}

O presente estudo teve como objetivo avaliar os níveis de alcoolemia, estabelecendo como ponto de corte o nível de $0,6 \mathrm{~g} / \mathrm{l}$ de álcool no sangue entre as vítimas fatais por acidentes de trânsito, na cidade do Rio de Janeiro, por meio de dados secundários dos registros do IML. Nesse sentido, a literatura mundial evidencia o impacto do álcool nos acidentes de trânsito e tem demonstrado a grande relevância desse tema como fator de risco real e maximizador na ocorrência de acidentes $^{(1,3,10,12)}$

$\mathrm{O}$ ato de dirigir um veículo sob o efeito de bebida alcoólica, mesmo com níveis de alcoolemia abaixo de 
0,6g/l, e, como exemplo, a França e outros países da Comunidade Européia com $0,5 \mathrm{~g} / \mathrm{l}$, na Austrália com $0,2 \mathrm{~g} / \mathrm{l}$ para a população jovem, pode representar efetivo e real fator de risco ${ }^{(10)}$.

Outros fatores coexistentes e eventuais como sonolência, cansaço, estresse/ansiedade, uso de medicamentos (inadequados e associados às bebidas alcoólicas) e a sensibilidade individual (suscetibilidade neurofuncional) sem dúvida se somam para a elevação perigosa do nível de risco dos acidentes de trânsito(3).

Outro aspecto que deve ser considerado se refere ao comportamento da curva do metabolismo natural do álcool, no organismo, e o próprio efeito comportamental relativo da ação do álcool sobre o cérebro(3). Nesse sentido, a verificação de um teste de alcoolemia abaixo de $0,6 \mathrm{~g} / \mathrm{l}$, no momento do acidente ou poucas horas após, não afasta, obviamente, o fato de que horas antes esse nível pudesse estar bem maior que $0,6 \mathrm{~g} / \mathrm{I}^{(13)}$. Esse fato aponta para a eventualidade, pouco considerada, no que tange ao rápido metabolismo e consequente queda da concentração de álcool no sangue.

Considerando essas premissas, o presente estudo faz parte da linha de pesquisa desenvolvida ao longo dos últimos cinco anos pela autora principal. Os resultados apresentados são, relativamente, significativos, sugerindo a necessidade de aprofundamento de estudos nessa temática, sobretudo por ser estudo pioneiro, apresentado por enfermeiro com essa temática, nessa área de investigação, na cidade do Rio de Janeiro. Uma das questões metodológicas que mostra necessariamente o aprimoramento refere-se à pouca regularidade de realização de exame de alcoolemia e de outras drogas em todas as vítimas de morte violenta, normalmente nos acidentes de trânsito, sendo que o Brasil se destaca no cenário da violência no mundo contemporâneo.

Assim, verificou-se, na Tabela 1, que, dos 348 (100\%) casos de vítimas fatais, apenas 94 (27\%) realizaram o teste da alcoolemia. Desses, a amostra constituiu-se por $83(23,8 \%)$ que apresentaram alcoolemia acima de $0,1 \mathrm{~g} / \mathrm{l}$. No período do estudo, considerando o nível recomendado para dirigir $(0,6 \mathrm{~g} / \mathrm{l}$ de álcool no sangue), de acordo com as diretrizes do Código de Trânsito Brasileiro, de 1997, 60\% das vítimas apresentaram alcoolemia acima do permitido por lei. Essa observação indica que significante parcela das vítimas fatais consumiu doses baixas de bebidas alcoólicas (40\%), ou que esse consumo ocorreu algumas horas antes do evento e do exame laboratorial, como descrito anteriormente, reforçando a necessidade de se rever e discutir sobre os níveis de alcoolemia, a exemplo de como ocorreu em outros países(8).
No caso, o Brasil está no ranking de altíssimos índices de mortalidade e morbidade causadas pelos acidentes de trânsito, em que o consumo de bebidas alcoólicas está diretamente envolvido. Daí a urgência da discussão e a implementação de medidas restritivas que possam contribuir para expressiva redução desses índices. Nesse sentido, países como a França, Espanha, Japão e outros obtiveram relevante sucesso na redução de mortalidade decorrente de acidentes de trânsito, por meio dessas medidas de controle do uso do álcool, entre as quais forte combate ao dirigir sob efeito do álcool(9).

Com relação à faixa etária e aos níveis de alcoolemia das vítimas fatais, conforme apresentado na Tabela 2 , observou-se predominância entre os mais jovens, 33 (38,5\%), vítimas com idade entre 20 e 39 anos. Ao avaliar o grupo com idade entre 20 e 50 anos, considerando uma população em fase economicamente ativa, mais da metade (54\%) são trabalhadores, com marcante potencial de vida produtiva. Entretanto, observa-se, também, que $18(21,7 \%)$ das vítimas apresentavam idade acima de 60 anos, na qual se encontra o maior número de pessoas vítimas de atropelamento.

No que se refere à taxa de alcoolemia, é importante destacar a constatação da concentração do álcool acima de $0,6 \mathrm{~g} / \mathrm{I}$ no grupo jovem de 20 a 49 anos, ou seja, $72,5 \%$ versus $27,5 \%$ com nível de alcoolemia abaixo de $0,6 \mathrm{~g} / \mathrm{l}$, mostrando a prevalência para o abuso e maior consumo de álcool no grupo mais jovem. Ao contrário, no grupo mais velho, 50 a 59 e 60 e mais (65\%), que mostrou alcoolemia inferior e $35 \%$ superior a $0,6 \mathrm{~g} / \mathrm{l}$. Portanto, esses dados são coerentes com a observação de diversos autores ${ }^{(3-4,10)}$ e com o senso comum de que os mais jovens possivelmente abusam mais das bebidas alcoólicas do que os mais velhos, considerando, ainda, que o idoso apresenta mais vulnerabilidade em relação ao uso de álcool e drogas quando comparado com as pessoas mais jovens ${ }^{(14)}$, dessa forma, incorporando sem dúvida, maior probabilidade ou riscos mais elevados em relação aos acidentes de trânsito.

Não se pode deixar de destacar, porém, que hoje, sobretudo no Brasil, há forte estímulo ao uso do álcool por meio da maciça propaganda dirigida às camadas jovens, como a própria indústria reconhece no foco das mensagens publicitárias. O forte aumento do consumo de bebidas alcoólicas, principalmente de cervejas, representa sério desafio para implementação de ações que visam reduzir os índices de morbimortalidade dos acidentes de trânsito e da violência urbana, em muitos $\operatorname{casos}^{(9)}$. 
Avaliando as informações sociodemográficas (Tabela 2), observam-se dados relevantes no que se refere ao consumo de álcool. A distribuição de vítimas fatais envolvidas com algum nível de alcoolemia, quanto ao sexo, mostra esperado predomínio de homens sobre as mulheres. Tal fato pode ser explicado pelo maior consumo de álcool nessa população.

A presença de alcoolemia acima de $0,6 \mathrm{~g} / \mathrm{l}$ foi nitidamente mais frequente no sexo masculino, dados que corroboram os da literatura.

Em relação ao estado civil, destacou-se o consumo de álcool entre os solteiros que, em geral, são mais jovens que os casados. Esses, provavelmente, são menos jovens e mais comprometidos com a família. Quando se avaliou os níveis de alcoolemia (maior ou menor que $0,6 \mathrm{~g} / \mathrm{l}$ ), entre os solteiros, observou-se que 70\% apresentaram níveis bem acima dos toleráveis, ao contrário do que se observou entre os casados. Mais uma vez esses dados apontam para o risco do condutor mais jovem em relação ao consumo do álcool.

Quando se compara acidentes de trânsito e o horário em que ocorreram, ressalta o que tem sido observado, isto é, os registros dos acidentes no período da noite e da madrugada, dados que corroboram aqueles da literatura ${ }^{(4,10)}$, demonstrando essa relação entre os níveis de alcoolemia e os casos fatais ocorridos na madrugada. Essa constatação mais uma vez indica o consumo de bebidas nos eventos festivos ou comemorativos, onde os jovens abusam do álcool sem moderação, tantas vezes divulgado nas propagandas. O número expressivo de alcoolemia elevada entre as vítimas fatais, no período da manhã, reforça o ponto de vista acima, no sentido do abuso de álcool na madrugada, véspera da manhã.

Nesse enfoque, os dias da semana que ocorreram os acidentes fatais também são condizentes com o problema, relacionados ao consumo de bebidas alcoólicas. Assim, de acordo com estudos nacionais e internacionais ${ }^{(3-4,12-13)}$, a concentração dos acidentes de trânsito com vítimas fatais predomina, nítidamente, nos fins de semana, conforme apresenta a Tabela 3, 58(60\%) dos acidentes fatais ocorreram no referido período. Devem ser ressaltados os níveis de alcoolemia que, apesar de a amostra ser relativamente pequena, onde nos três dias predominou os níveis acima de $0,6 \mathrm{~g} / \mathrm{l}(60 \%)$, esse fato não ocorreu nos demais dias avaliados.

Na Tabela 3, ainda, se destaca e se apresenta, em consonância com outros estudos, o que se refere ao local em que ocorreu o óbito(4,10). Como no caso a via pública foi o local de maior frequência da ocorrência de casos fatais associada à alcoolemia acima de $0,6 \mathrm{~g} / \mathrm{l}$, por outro lado, nos casos de óbito nos hospitais, a ocorrência foi em menor proporção e a alcoolemia foi em menor escala.

\section{Conclusão}

Pode se concluir que os maiores índices de alcoolemia estiveram presentes em vítimas mais jovens, do sexo masculino, solteiros e as características relacionadas às ocorrências foram predominantes no final de semana, geralmente no período da noite e da madrugada, características consideradas como potenciais para riscos reais de acidentes de trânsito com vítimas fatais, que podem ser previsíveis,e, por isso, passíveis de prevenção.

É preciso levar em consideração alguns fatores limitantes de uma análise mais aprofundada do presente estudo como, por exemplo, a impossibilidade de melhor avaliação em relação à alcoolemia examinada nas vítimas e sua posição dentro da dinâmica do acidente. Nesse sentido, faz-se necessário estudos posteriores, maior detalhamento em relação à alcoolemia e à posição das vítimas no evento: atropelado versus condutor e motoristas versus passageiros.

Por fim, o estudo traz contribuições não apenas para a área de enfermagem no sentido de trabalhar as intervenções breves para redução e controle do uso do álcool, nos diversos grupos populacionais, mas também para melhor efetivação de políticas públicas voltadas para o uso e abuso de álcool, e, nesse sentido, comprometendo todos os profissionais no envolvimento e planejamento de trabalhos preventivos ${ }^{(15)}$, voltados aos diversos grupos da população e a todos os níveis do beber.

\section{Agradecimentos}

Agradecemos a Comissão Interamericana para o Controle do Abuso de Drogas/CICAD da Secretaria de Segurança Multidimensional/SSM da Organização dos Estados Americanos/OEA, a Secretaria Nacional de Políticas sobre Drogas/SENAD do Gabinete de Segurança Institucional/Brasil, a Escola de Enfermagem de Ribeirão Preto da Universidade de São Paulo e o Centro Colaborador da Organização Mundial da Saúde para o Desenvolvimento da Pesquisa em Enfermagem, a população representada nas pesquisas, bem como as autoridades das universidades representadas pelos participantes do Programa On-Line de Especialização em Pesquisa sobre o Fenômeno das Drogas - PREINVEST, períodos 2005, 2006, 2007 e 2008. 


\section{Referências}

1. Organización Mundial de la Salud - OMS. Informe mundial sobre prevención de los traumatismos causados por el trânsito. Ginebra (SW): OMS; 2004.

2. Ministério da Saúde (BR). [Página de Internet]. Brasília: Ministério da Saúde. Evolução da Mortalidade por violência no Brasil e regiões. [35 telas] [Acesso em: maio 2008]. Disponível em: http://www.saude.gov.br.

3. Lima JMB. Alcoologia. O alcoolismo na perspectiva da Saúde Pública. Rio de Janeiro (RJ): Med Book Editora Cientifica; 2007.

4. Abreu AMM, Lima JMB, Silva LM. Níveis de alcoolemia e mortalidade por acidentes de trânsito na cidade do Rio de Janeiro. Esc Anna Nery Rev Enferm. 2007 Dezembro, 11(4):575-80.

5. Orosco R, Borges G, Mondragón L, Monroy-Nasr Z. El lugar donde ocurren lãs lesiones y su relacion com el uso de alcohol. Estúdio em sala de urgências. Salud Mental, México 2005 Octubre; 28(5):50-6.

6. Lima JMB, Abreu AMM. Álcool e os Acidentes de Trânsito: Estudo preliminar sobre mortalidade. In: Gigliotti AA, Guimarães $A$, editors. Dependência, Compulsão e Impulsividade. Rio de Janeiro (RJ): Ed Rubio; 2006.

7. Lei no 9503 de 23 de setembro de 1997. Institui o Código de Transito Brasileiro. [Acesso em: maio 2008]. Disponível em http:www.senado.gov.br/web/codigos/transito/httoc.htm

8. Velásquez HA, Eastman CA. Segurança no Transito: um problema de política pública. Washington (DC): Organização Panamericana de Saúde - OPAS; 2004.

9. Lima JMB. VII Congresso Latino Americano de Acidentes de Trânsito, ABRAMET. Palestra Temática Alcoolemia e os Acidentes de Trânsito; 2007. Setembro 07-09; Porto Seguro, Bahia; 2007.
10. Abreu AMM. Mortalidade nos acidentes de transito na cidade do Rio de Janeiro relacionada ao uso e abuso de bebidas alcoólicas [tese]. Rio de Janeiro (RJ): Escola de Enferm Anna Nery/UFRJ; 2006.

11. Lei no 11705 , de 19 de junho de 2008 (BR). Altera a lei no 9503, de 23 de setembro de 1997, que "institui o Código de Transito Brasileiro", e a lei 9294, de 15 de julho de 1996, que dispõe sobre as restrições ao uso e a propaganda de produtos fumígeros, bebidas alcoólicas, medicamentos, terapias e defensivos agrícolas, nos termos do $\S 4^{\circ}$ do art.220 da Constituição Federal, para inibir o consumo de bebidas alcoólicas por condutor de veículo automotor, e da outras providencias. [on line]. [Acesso em: 18 dezembro 2008]. Disponível em: http:// planalto.gov.br/

12. Kaisa R, Isohanni I, Jokelainen J, Taanila A, Isohanni M, Räsänen $P$. Low educational performance is associated with drink during: a 31 year follow-up of the northern Finland 1966 Birth Cohort. Alcohol Alcoholis. 2003; 38(3):219-23.

13. Zumwalt R, Bost R, Sunshine I. Evaluations of ethanol concentrations in decomposed bodies. J Forensic Sci 1982 July; 27(3):549-55.

14. Castilho BAA, et al. Situações estressantes de vida, uso e abuso de álcool e drogas em idosos de Monterrey, México. Rev. Latino-Am Enfermagem. 2008 maio-junho; 16(especial): 509-15.

15. Pillon SC, Luís MAV. Modelos explicativos para o uso de álcool e drogas e a prática de enfermagem. Rev. Latino-Am. Enfermagem. 2004; 12(4):676-2. 